\title{
The Impact of a Web Banner Position on the Webpage User Experience
}

\author{
Snježana Ivančić Valenko*, Damira Keček, Marko Čačić, Katarina Slanec
}

\begin{abstract}
Visual perception of a web banner depends on different parameters. Webpage template configuration and web banner position are important parameters that can affect the banner visibility. This paper aims to determine the impact of a web banner position on the banner visibility and webpage user experience. Research was conducted by using an eye tracking technology. Four webpage templates were created for two groups of respondents. Webpage templates were based on a news portal wireframe and six different banners. Each respondent was exposed to the same set of four different web banners on left and right positions, but their placement on the webpage was changed for each group of respondents, while template complexity remained the same. Two other banners placed on the top position remained the same for both groups, since the emphasis is on evaluation of left and right web banner positions. Research results indicate that the web banner on the left position is noticed before the web banner on the right position. Although the web banner on the left position is noticed before, the web banner on the right position is on average viewed for a longer time. The analysis of a different web banner positions provides guidelines for web designers to improve web banner visibility and overall webpage user experience.
\end{abstract}

Keywords: banner position; banner visibility; eye tracking; user experience; web banner; webpage

\section{INTRODUCTION}

Websites are very important advertising outlets in the modern world since World Wide Web is the most popular media of today's information society. Advertisements are most often incorporated into websites as web banners, which can be static or even animated. Visual perception of a web banner depends on different parameters. According to Cho and Cheon [1], if visitors perceive banners as obstacles to achieving a certain goal, they are more likely to ignore them.

Graphic design of a web banner, webpage template configuration and banner's position on a webpage layout are important parameters that can greatly affect the webpage user experience. Most users tend to view webpage areas that are known as banner positions, such as top, left, and right side of the webpage. This paper aims to determine the impact of a web banner position on the banner visibility and webpage user experience. More precisely, banners on the left and right side of the webpage layout were observed. Some of the presented methods and results are based on work completed as part of the student final thesis entitled The impact of graphic elements of web user interface on the user experience [2].

\section{PREVIOUS RESEARCH OVERVIEW}

Effectiveness of a static banner placed on different positions on the screen was explored by Muñoz-Leiva et al. [3]. Four templates and four groups of participants were analysed. Each version of a template had static banner on different position: bottom-right, bottom-left, top-left and topright of the webpage. Authors concluded that banners placed on the bottom-right and bottom-left positions are less visible and receive less attention. They also note that top-right is the best position on the screen, and banner on that side will be longer viewed. Different results that indicate participants are focused more on top and left of the page than other positions were obtained by Güner and İnal [4]. Calisir and Karaali [5] based their research on top-left, top-center and top-right positions on the webpage layout.
John and Sathiyaseelan [6] concluded that the position of an online banner affects its effectiveness. They observed four web banner positions - at right and left side, top and bottom of the webpage. Authors concluded that banner placed on the top of the webpage is noticed better than banner on the right position. There was no significant difference between left and right web banner positions. The same results were obtained by Goodrich [7].

The impact of banner format and animation on banner effectiveness is investigated by $\mathrm{Li}$ et al. [8]. Two banner formats (vertical banner on the side of the webpage and horizontal banner at the top of the webpage), and three types of animation (high, low, and static) were used. Horizontal banners were attracting more interactions than vertical banners, but vertical banners held user's attention longer than horizontal. Animated banners attracted more attention than static banners. Opposite results indicating that static banner attracted more attention were obtained by Lee and Ahn [9].

\section{RESEARCH OBJECTIVES AND METHODOLOGY}

The purpose of research in this paper was to examine the impact of left and right web banner positions on the banner visibility and webpage user experience.

In this research each respondent was exposed to the same set of web banners, but their placement on the webpage was changed for each group of respondents, while template complexity remained the same. The main hypothesis is that the banner positioned on the left side of the webpage will be noticed before the one positioned on the right side. That prediction is based on the conclusions made by Nielsen [10]. $\mathrm{He}$ discovered that web content is being read in F-shaped pattern, so we expect that the same observations are appliable to the web banners used in this research. Besides testing the beforementioned hypothesis, aim is to determine how long will respondents look on certain web banner position and then draw usable conclusions from study results.

Research in this paper was conducted by using a customized webpage templates that were based on a news portal wireframe and six different banners. Research involved first-year students of the Multimedia, design and 
application undergraduate professional study at the University North in Varaždin, Croatia. Students were divided into two groups of respondents. Their task was to observe prepared templates while being recorded by the eye-tracking device. First group of respondents had to observe two webpage templates that displayed the news and three banners, one placed on the left and other on the right side of the webpage's main container, while third was placed on the top position, under navigation bar. Second group of respondents observed other two webpage templates that had news sections identical to the ones displayed on the templates for the first group, but left and right banners switched positions, while top banner remained intact. Banners that previously were on the left side of the webpage's main container now were placed on the right side, and vice versa.

Templates were prepared and displayed to the respondents as $1905 \times 915 \mathrm{px}$ webpage layout pictures, without scaling, on a 21.5" Samsung LCD screen, model $\mathrm{S} 22 \mathrm{~A} 350 \mathrm{H}$. Screen aspect ratio was 16:9 and display resolution was set to the $1920 \times 1080 \mathrm{px}$. Relevant measurements were performed by the Gazepoint GP3 Desktop eye tracking device and processed by the Gazepoint Analysis 3.5.0 software.

In order to get precise and accurate measurements, eyetracking device was recalibrated for every respondent. For some respondents recalibration could not be successfully performed, so they did not participate in this research. The respondent's distance from the screen was in the range of 60 to $80 \mathrm{~cm}$ and their face was parallel to the screen. Two webpage templates were shown to the respondents, each for 10 seconds.

\subsection{Webpage Template Design}

Webpage templates were designed to inspect web banner visibility and relevant parameters of the webpage user experience. Visual appearance of banners is based on randomly selected parameters since the emphasis of this research is on web banner position, not design elements.

One of the potentially most influential visual parameters is banner's background colour. Its impact was analysed by Lapa [11], also with eye-tracking device. Author observed banners that had either a white background with black text or white text on a coloured background. Research results showed that the banner background colour does not affect user behaviour [11].

According to the literature review, complexity of the webpage is more important parameter for this kind of research. Liu et al. [12] note that complexity of the webpage is very important as it affects the first fixation on the banner.

Four webpage templates were created for two groups of respondents. Webpage templates were based on a news portal wireframe and six different banners. Each respondent was exposed to the same set of four different web banners on left and right positions, but their placement on the webpage was changed for each group of respondents, while template complexity remained the same. Two other banners placed on the top position remained the same for both groups, since the emphasis is on evaluation of left and right web banner positions.

\subsubsection{Webpage Templates for the First Group of Respondents}

Fig. 1 shows the first webpage template for the first group of respondents. The template displays the main news, several other accompanying news on the page, and three different web banners, one positioned on the left, second on the right side of the webpage's main container, while third is placed on the top position. Left banner is named Banner_A, right banner is Banner_B, and top banner is Banner_E.

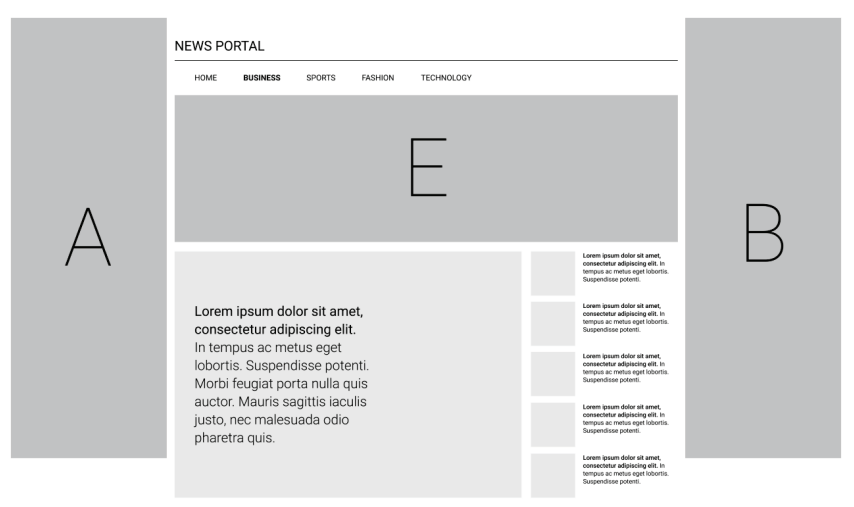

Figure 1 First webpage template for the first group of respondents

Second webpage template for the first group of respondents is shown in Fig. 2. The template structure is identical to the previous one, but content is different. As first webpage template, it shows the main news, several other accompanying news on the page, and three different web banners - one positioned on the left, second on the right side of the webpage's main container, and third is placed on the top position. Left banner is named Banner_C, right banner is Banner_D, and top banner is Banner_F.

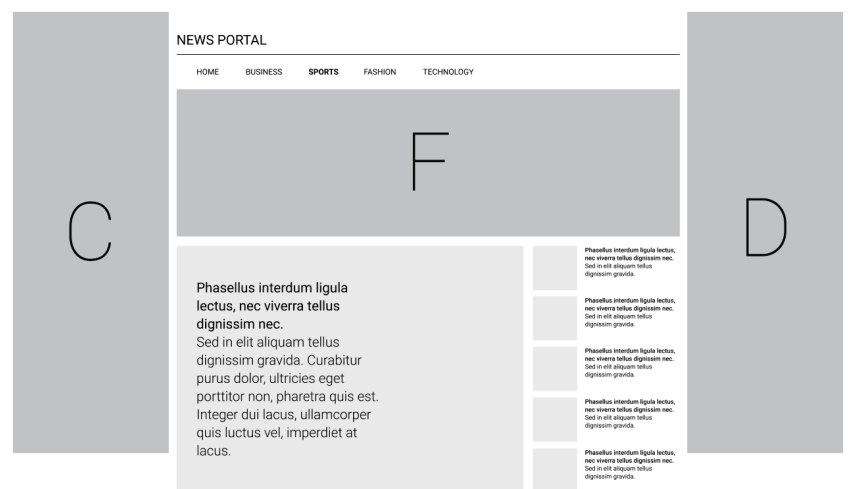

Figure 2 Second webpage template for the first group of respondents

\subsubsection{Webpage Templates for the Second Group of Respondents}

Webpage templates for the second group of respondents are based on the same concept as the ones for the first group. Content of each template is same as previous, but banners switched positions. Left and right banners were swapped to determine if the web banner position affects its visibility, while top banner remained intact. Fig. 3 shows the first webpage template for the second group of respondents. 

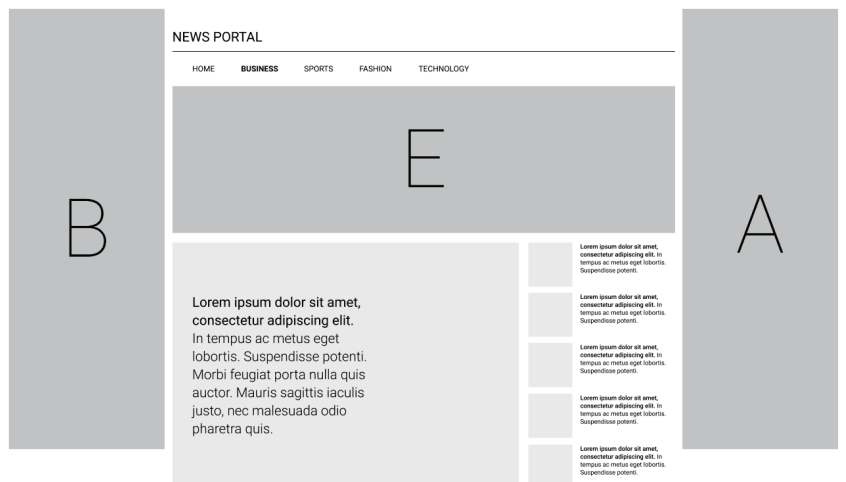

Figure 3 First webpage template for the second group of respondents

Similarly, Fig. 4 shows the second webpage template for the second group of respondents.

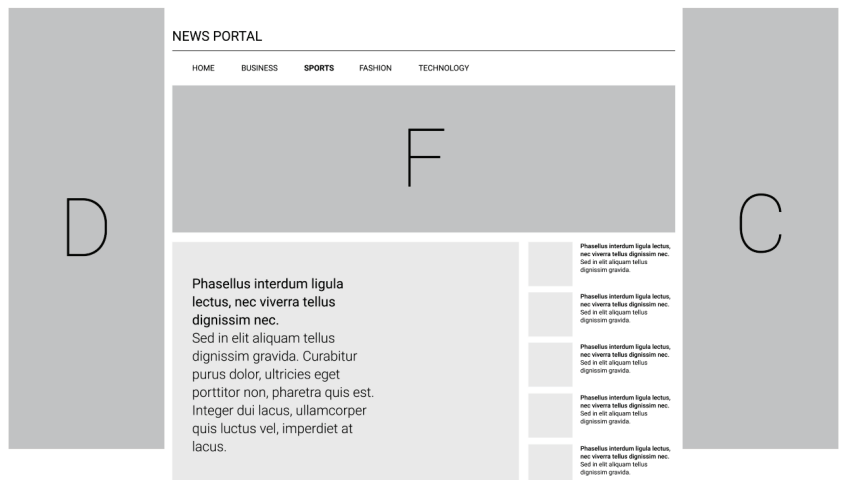

Figure 4 Second webpage template for the second group of respondents

\section{STATISTICAL ANALYSIS AND RESULTS}

In order to determine statistically significant differences in the time that each banner was viewed with regard to its position, a t-test for independent samples was applied. Before testing the hypothesis that the means of two groups are equal, homogeneity of variances of the populations from which the samples were selected was tested using the Levene test. According to the results of the Levene test, in all analysed cases the variances are homogeneous. The differences confirmed at $p<0.05$ were considered statistically significant.

Descriptive statistics, Levene and t-test results for the time that Banner_A and Banner_B were viewed regarding to their position are shown in Tab. 1. On average, the Banner_A on the right position was viewed longer than when it was placed on the left position, but difference in the recorded view times was not confirmed as statistically significant $(p>$ $0.05)$. The same conclusion can be drawn for the Banner_B.

Tab. 2 shows descriptive statistics, Levene and t-test results for the time that Banner $\mathrm{C}$ and Banner $\mathrm{D}$ were viewed regarding to their position on the webpage. Banner_C on the left position was on average viewed longer than the same banner on the right position. Banner_D on the right position was on average slightly longer viewed than the same banner on the left position. According to the t-test results, significant difference in arithmetic means in both banners was not confirmed $(p>0.05)$.

According to the research results presented in Tab. 3, the time to first view of the Banner_B on the right position is on average twice as long as the same banner on the left position, and this difference is statistically significant $(p<0.05)$. The time to first view of the Banner_A on the left position is on average slightly longer than the same banner on the right position, but the significant difference in arithmetic means in this case has not been confirmed $(p>0.05)$.

The results show that the time to first view of Banner_C and Banner $\mathrm{D}$ on the right position is on average longer than on the left position (Tab. 4). Differences in the time to first view of both banners with respect to their position on the webpage are statistically significant $(p<0.05)$.

Table 1 Descriptive statistics, Levene and t-test results for the time that Banner_A and Banner_B were viewed regarding to their position

\begin{tabular}{|c|c|c|c|c|c|c|c|c|c|c|}
\hline \multirow{3}{*}{ Time viewed (s) } & \multicolumn{6}{|c|}{ Banner position } & \multirow{2}{*}{\multicolumn{2}{|c|}{ Levene test }} & \multirow{2}{*}{\multicolumn{2}{|c|}{ t-test }} \\
\hline & \multicolumn{3}{|c|}{ Left } & \multicolumn{3}{|r|}{ Right } & & & & \\
\hline & $N$ & Mean (s) & Standard deviation (s) & $N$ & Mean (s) & Standard deviation (s) & $F$ & $p$ & $t$ & $p$ \\
\hline Banner_A & 29 & 1.09 & 1.15 & 25 & 1.21 & 0.89 & 0.161 & 0.689 & -0.438 & 0.663 \\
\hline Banner_B & 27 & 0.92 & 0.64 & 22 & 1.16 & 0.94 & 2.444 & 0.125 & 1.063 & 0.293 \\
\hline
\end{tabular}

Table 2 Descriptive statistics, Levene and t-test results for the time that Banner C and Banner D were viewed regarding to their position

\begin{tabular}{|c|c|c|c|c|c|c|c|c|c|c|}
\hline \multirow{3}{*}{ Time viewed (s) } & \multicolumn{6}{|c|}{ Banner position } & \multirow{2}{*}{\multicolumn{2}{|c|}{ Levene test }} & \multirow{2}{*}{\multicolumn{2}{|c|}{ t-test }} \\
\hline & \multicolumn{3}{|c|}{ Left } & \multicolumn{3}{|r|}{ Right } & & & & \\
\hline & $N$ & Mean (s) & Standard deviation $(\mathrm{s})$ & $N$ & $\operatorname{Mean}(\mathrm{s})$ & Standard deviation (s) & $F$ & $p$ & $t$ & $p$ \\
\hline Banner_C & 28 & 1.18 & 1.06 & 31 & 1.04 & 0.75 & 0.746 & 0.391 & 0.598 & 0.552 \\
\hline Banner_D & 29 & 1.23 & 0.71 & 21 & 1.38 & 0.88 & 1.476 & 0.230 & 0.674 & 0.504 \\
\hline
\end{tabular}

Table 3 Descriptive statistics, Levene and t-test results for the time to first fixation on the Banner_A and Banner_B regarding to their position

\begin{tabular}{|c|c|c|c|c|c|c|c|c|c|c|}
\hline \multirow{3}{*}{$\begin{array}{l}\text { Time to first } \\
\text { fixation (s) }\end{array}$} & \multicolumn{6}{|c|}{ Banner position } & \multirow{2}{*}{\multicolumn{2}{|c|}{ Levene test }} & \multirow{2}{*}{\multicolumn{2}{|c|}{ t-test }} \\
\hline & \multicolumn{3}{|c|}{ Left } & \multicolumn{3}{|r|}{ Right } & & & & \\
\hline & $N$ & Mean (s) & Standard deviation (s) & $N$ & Mean (s) & Standard deviation (s) & $F$ & $p$ & $t$ & $p$ \\
\hline Banner_A & 29 & 3.88 & 2.57 & 25 & 3.60 & 2.16 & 0.547 & 0.463 & 0.631 & 0.531 \\
\hline Banner_B & 27 & 2.96 & 2.10 & 22 & 5.90 & 2.13 & 0.104 & 0.748 & -4.688 & 0.000 \\
\hline
\end{tabular}


Table 4 Descriptive statistics, Levene and t-test results for the time to first fixation on the Banner_C and Banner_D regarding to their position

\begin{tabular}{|c|c|c|c|c|c|c|c|c|c|c|}
\hline \multirow{3}{*}{$\begin{array}{l}\text { Time to first } \\
\text { fixation (s) }\end{array}$} & \multicolumn{6}{|c|}{ Banner position } & \multirow{2}{*}{\multicolumn{2}{|c|}{ Levene test }} & \multirow{2}{*}{\multicolumn{2}{|c|}{ t-test }} \\
\hline & \multicolumn{3}{|c|}{ Left } & \multicolumn{3}{|c|}{ Right } & & & & \\
\hline & $N$ & Mean (s) & Standard deviation $(\mathrm{s})$ & $N$ & Mean (s) & Standard deviation $(\mathrm{s})$ & $F$ & $p$ & $t$ & $p$ \\
\hline Banner_C & 28 & 3.23 & 2.84 & 31 & 4.92 & 3.19 & 0.697 & 0.407 & -2.141 & 0.037 \\
\hline Banner_D & 29 & 2.76 & 2.62 & 21 & 5.63 & 3.01 & 0.971 & 0.329 & 3.594 & 0.001 \\
\hline
\end{tabular}

\section{HEAT MAP ANALYSIS}

Fig. 5, 6, 7 and 8 present heat maps generated by first and second group of respondents. Heat maps are showing visual attention of respondents and illustrate differences in perception between observed webpage templates and implemented banners.

By comparing Fig. 5 and Fig. 6, it can be concluded that the banner on the left side of the webpage is noticed first, while banner on the right is viewed in more detail.

Fig. 5 contains the overall average of what the first group of respondents observed in the first template. The red and orange colour on the heat map indicates that the respondents did not only watch, but also read the content of the main news. The content above the main news was also viewed and read but less than main news. The content of the left banner was viewed slightly more than the right banner, but the top part of the right banner was read more.

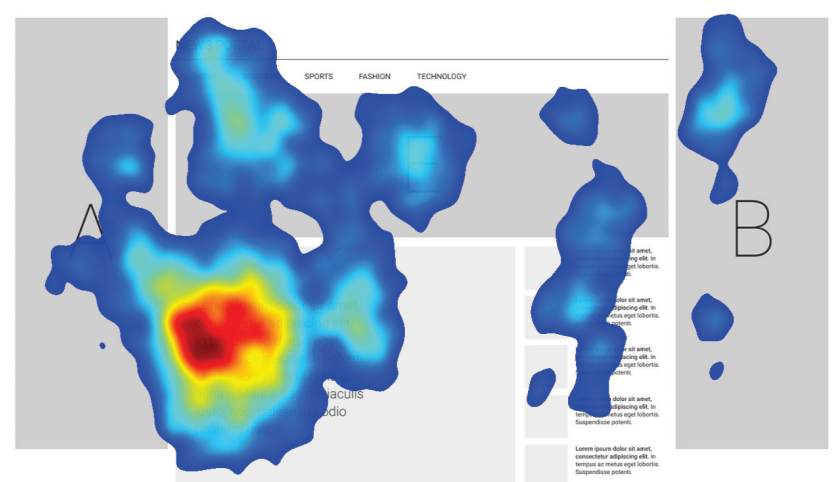

Figure 5 Heat map generated by first respondent group observing first webpage template

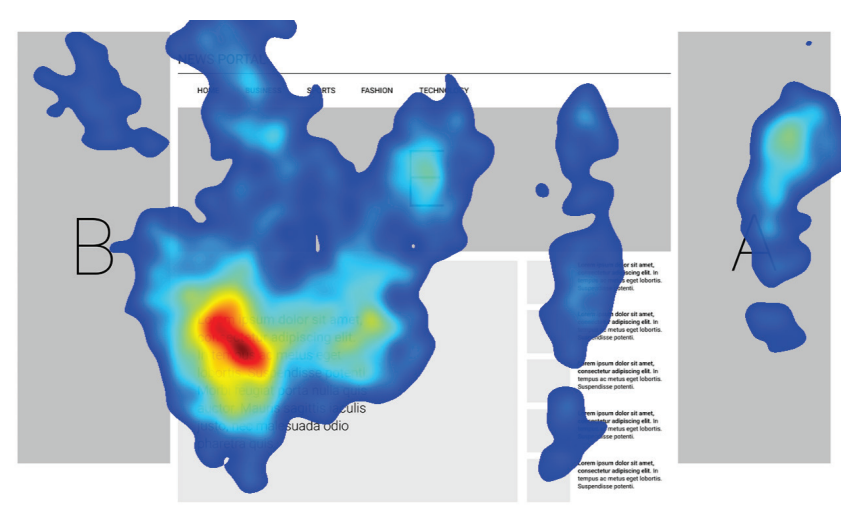

Figure 6 Heat map generated by second respondent group observing first webpage template

Fig. 6 contains the overall average of what was observed by the second group of respondents in the first template. This group of respondents observed Banner_A longer than previous group. It is obvious that the same banner was longer viewed when it was placed on the right position, than when it was on the left side of the webpage.

Fig. 7 contains the overall average of what the first group of respondents observed in the second template. The content of the left banner is viewed to the same extent as the right, but part the right banner was noticed much more.

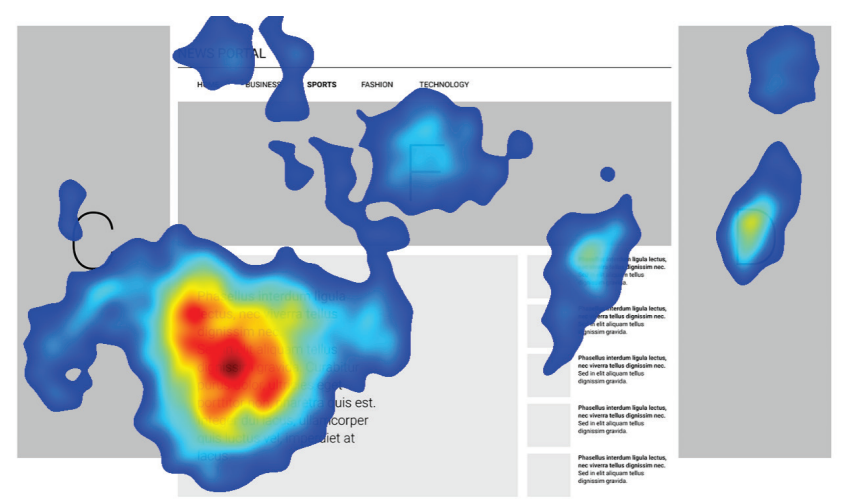

Figure 7 Heat map generated by first respondent group observing second webpage template

Fig. 8 contains the overall average of what the second group of respondents observed in the second template.

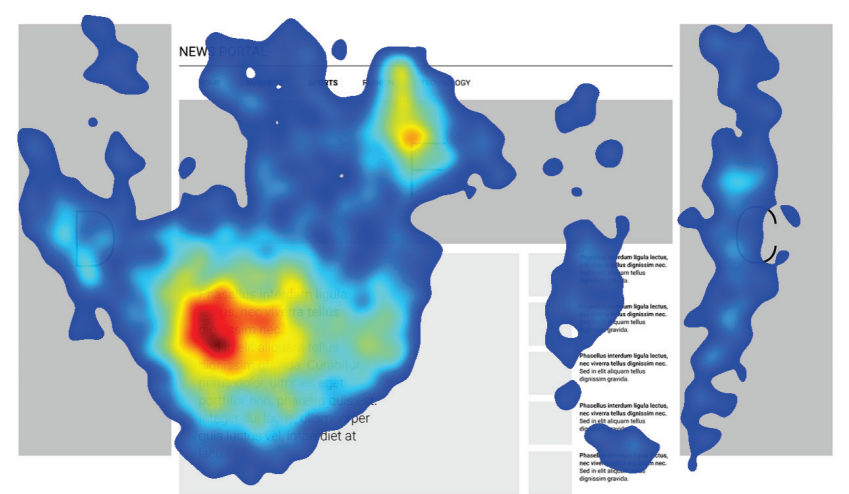

Figure 8 Heat map generated by second respondent group observing second webpage template

This group of respondents, unlike the previous one, equally noticed banners on the left and right side of the webpage. If we compare heatmap of Banner_C placed on the right position (Fig. 7) with the heatmap of the same banner placed on the left position (Fig. 8) it is obvious that it is much less viewed when placed on the left position.

In the Fig. 8, there was a deviation in that the left banner was viewed longer than the right, which was not the case in the previous three examples. This is attributed to the content of the banner itself. Incorporated graphic design components attracted the attention of the respondents, so it can be said 
that with carefully selected graphic elements the area of interest can be redirected to another area.

Respondents first noticed the upper left side of the web banner, and later the right. Observation is in line with Nielsen's F-shape theory [10] which predicts that web content is being read from top to bottom and from left to right.

\section{CONCLUSIONS}

The aim of research in this paper was to determine the impact of left and right web banner positions on the banner visibility and webpage user experience. Research was conducted by using an eye tracking technology and customized webpage templates with integrated set of banners.

Four webpage templates were created for two groups of respondents. Webpage templates were based on a news portal wireframe and six different banners. Each respondent was exposed to the same set of four different web banners on left and right positions, but their placement on the webpage was changed for each group of respondents, while template complexity remained the same. Two other banners placed on the top position remained the same for both groups, since the emphasis is on evaluation of left and right web banner positions.

According to the research results, respondents in the first seconds of the conducted experiment mostly noticed the central part of the webpage, which was expected due to the layout configuration. The banner on top of the webpage was noticed before the main news.

Research results indicate that the web banner on the left position is noticed before the web banner on the right position. Although the web banner on the left position is noticed before, the web banner on the right position is on average viewed for a longer time and in more detail. Respondents first noticed the upper left side of the web banner, and later the right. Since the banner positioned on the left side of the webpage is noticed before the one positioned on the right side, the main hypothesis is confirmed.

Observations are in line with Nielsen's study [10] which states that web content is being read in F-shaped pattern, from top to bottom and from left to right. Future research could involve additional control survey that will question what respondents saw on the certain web banner. That additional information could be used in the process of web banner position efficiency determination and provide additional insights for advertising optimization.

\section{REFERENCES}

[1] Cho, C. \& Cheon, H. J. (2004). Why do people avoid advertising on the internet? Journal of advertising, 33(4), 8997. https://doi.org/10.1080/00913367.2004.10639175

[2] Slanec, K. (2021). The impact of graphic elements of web user interface on the user experience (Final thesis). Retrieved from https://urn.nsk.hr/urn:nbn:hr:122:214716

[3] Muñoz-Leiva, F., Faísca, L. M., Ramos, C. M., Correia, M. B., Sousa, C. M., \& Bouhachi, M. (2021). The influence of banner position and user experience on recall. The mediating role of visual attention. Spanish Journal of Marketing-ESIC. https://doi.org/10.1108/SJME-04-2020-0050

[4] Güner, H. \& İnal, Y. (2015, August). The effect of banner location on banner recognition in a Turkish government website: an eye tracking study. In International Conference on Human-Computer Interaction (pp. 65-72). Springer, Cham. https://doi.org/10.1007/978-3-319-21006-3_7

[5] Calisir, F. \& Karaali, D. (2008). The impacts of banner location, banner content and navigation style on banner recognition. Computers in Human Behavior, 24(2), 535-543. https://doi.org/10.1016/j.chb.2007.02.019

[6] John, D. A. \& Sathiyaseelan, A. (2014). The effect of the positioning of webpage banner advertisements on implicit and explicit memory. Global Journal of Commerce \& Management Perspective, 3(2), 120-124.

[7] Goodrich, K. (2007). Optimal positioning of Web page banner advertisements: An extension of hemispheric processing theory. Florida Atlantic University.

[8] Li, K., Huang, G., \& Bente, G. (2016). The impacts of banner format and animation speed on banner effectiveness: Evidence from eye movements. Computers in Human Behavior, 54, 522530. https://doi.org/10.1016/j.chb.2015.08.056

[9] Lee, J. \& Ahn, J. H. (2012). Attention to banner ads and their effectiveness: An eye-tracking approach. International Journal of Electronic Commerce, 17(1), 119-137. https://doi.org/10.2753/JEC1086-4415170105

[10] Nielsen, J. (2006). F-shaped Pattern for Reading Web Content (original study) Retrieved from https://www.nngroup.com/articles/f-shaped-pattern-readingweb-content-discovered/

[11] Lapa, C. (2007). Using eye tracking to understand banner blindness and improve website design. Rochester Institute of Technology. RIT Digital Media Library.

[12] Liu, W., Liang, X., \& Liu, F. (2019). The effect of webpage complexity and banner animation on banner effectiveness in a free browsing task. International Journal of Human-Computer Interaction, 35(13), 1192-1202. https://doi.org/10.1080/10447318.2018.1516843

Authors' contacts:

Snježana Ivančić Valenko, senior lecturer (Corresponding author)

University North,

Jurja Križanića 31b, 42000 Varaždin, Croatia

snjezana.ivancic@unin.hr

Damira Keček, PhD, Assist. Prof.

University North,

Jurja Križanića 31b, 42000 Varaždin, Croatia

damira.kecek@unin.hr

Marko Čačić, PhD

University North,

Jurja Križanića 31b, 42000 Varaždin, Croatia

marko.cacic@unin.hr

Katarina Slanec, bacc. ing. techn. graph.

University North,

Jurja Križanića 31b, 42000 Varaždin, Croatia

katarina.slanec@gmail.com 